\title{
Correction to: Optimal coupling combinations between dripper discharge and irrigation interval of maize for seed production under plastic film-mulched drip irrigation in an arid region
}

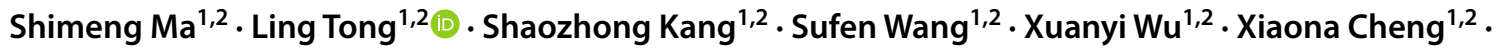 \\ Qiangqiang $\mathrm{Li}^{1,2}$
}

Published online: 27 October 2021

(c) Springer-Verlag GmbH Germany, part of Springer Nature 2021

\section{Irrigation Science https://doi.org/10.1007/} s00271-021-00739-x

In the original article, the Fig. 1 was published with in inaccuracies. The correct figure is given below.

The original article has been corrected.

2 Wuwei Experimental Station for Efficient Water Use in Agriculture, Ministry of Agriculture and Rural Affairs, Wuwei 733000, Gansu, China 

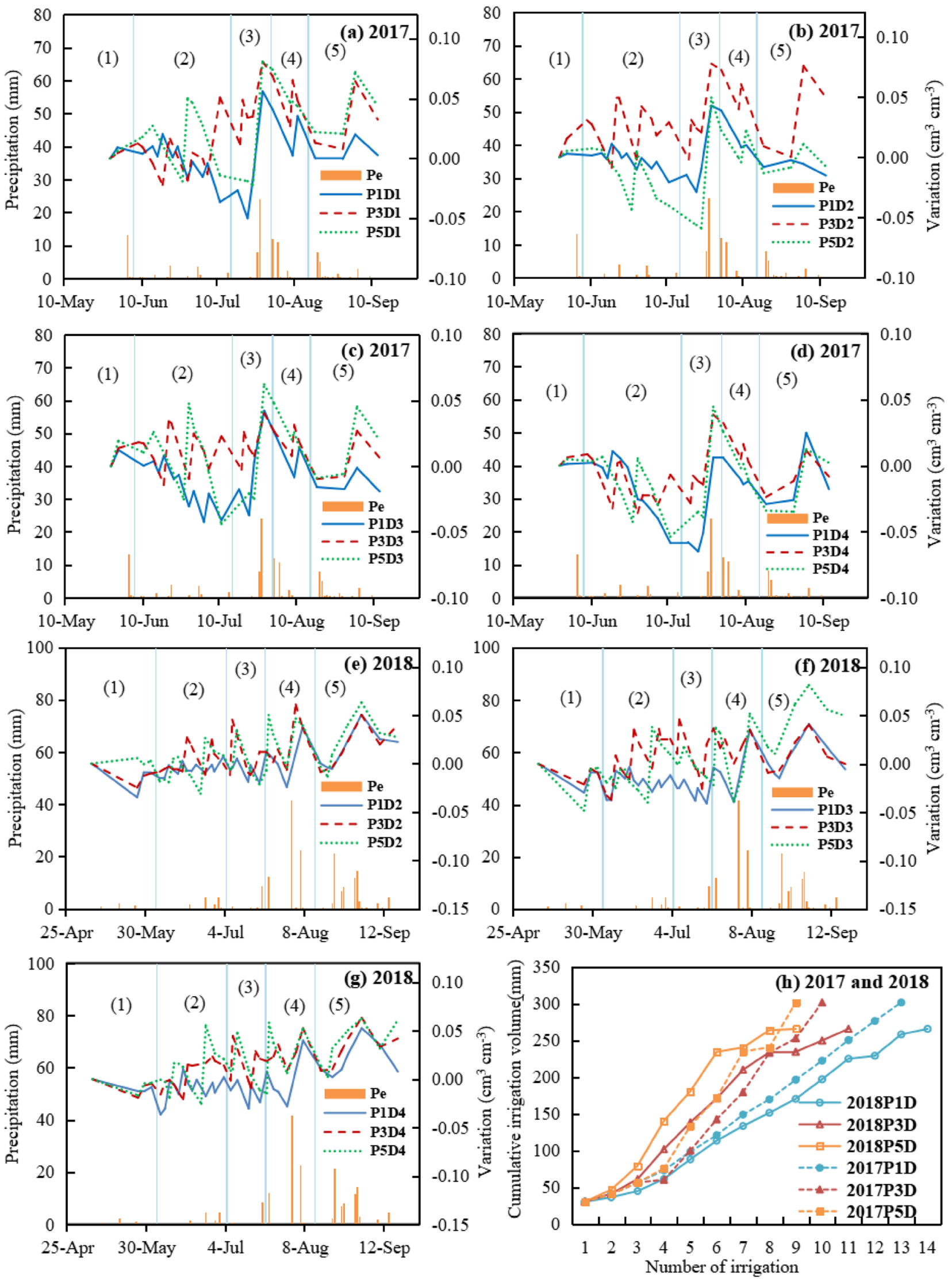
४Fig. 1 The change in soil water content variation (averaged within 0-60 cm soil depth) and rainfall with time $(\mathbf{a}-\mathbf{g})$, along with the cumulative irrigation amount curve under different treatments (h). D1, D2, D3, D4 are the dripper discharges of 1.38, 2.0, 2.5, 3.0 $\mathrm{L} \mathrm{h}^{-1}$, respectively. P1, P3, P5 are the irrigation intervals at $6,10,14$ days, respectively. $P_{e}$ stands for the effective precipitation. (1), (2), (3), (4), (5) represent the seedling stage, the jointing stage, the heading stage, the filling stage, and the maturation stage, respectively. P1D are treatments with an irrigation interval of P1. P3D are treatments with an irrigation interval of $\mathrm{P} 3$. P5D are treatments with an irrigation interval of P5

Publisher's Note Springer Nature remains neutral with regard to jurisdictional claims in published maps and institutional affiliations. 